\title{
Sorption characteristics of ready-made mixtures containing oatflakes, apples, and cinnamon
}

\author{
Albena Durakova ${ }^{1, *}$, Adelina Vasileva $^{2}$ and Kornelia Choroleeva ${ }^{3}$ \\ ${ }^{1 *}$ Department of Process Engineering, University of Food Technologies - Plovdiv, 26 Maritza Blvd. \\ BG-4002 Plovdiv, Bulgaria \\ ${ }^{2}$ Department of Mechanical and Instrument Engineering, Technical University - Sofia, Plovdiv \\ Branch, 25 Tsanko Duistabanov Str., Plovdiv 4000, Bulgaria \\ ${ }^{3}$ Language Training Centre, University of Food Technologies - Plovdiv, 26 Maritza Blvd. BG-4002 \\ Plovdiv, Bulgaria
}

\begin{abstract}
The present paper studies the sorption characteristics of readymade mixtures containing oatflakes $-89.5 \%$, apples $-10 \%$, and cinnamon $-0.5 \%$ at the temperatures of $10^{\circ} \mathrm{C}, 25^{\circ} \mathrm{C}$ and $40^{\circ} \mathrm{C}$ and for eight water activities in the $11 \%-85 \%$ range. The results obtained demonstrate that at a constant water activity, the increase in temperature is coupled with a decrease in equilibrium moisture content. The sorption isotherms of the analyzed ready-made mixture belong to Type III according to the classification of Brunauer et al. In order to describe the isotherms following the evaluation criteria, that is mean relative error, standard deviation, and distribution of residuals, the study recommends the threeparameter modified Oswin for adsorption and the Henderson model for desorption. Via linearization of the Brunauer-Emmett-Teller model, we calculate the values of monolayer moisture content (MMC) at aw $<0.5$ for both processes. For adsorption, the MMC falls within the $2.51 \%-3.57 \%$ d.b. range, whereas for desorption it is within the $3.41 \%-3.71 \%$ d.b. range. Temperature affects the MMC since its increase leads to a decrease in the MMC for both processes. For adsorption, at a temperature between $10^{\circ} \mathrm{C}$ and $40^{\circ} \mathrm{C}$ the MMC decreases by $1.06 \%$, and for desorption - by $0.3 \%$.
\end{abstract}

Keywords: ready-made mixtures, oatflakes, apple, cinnamon

\section{Introduction}

Latest years have witnessed the increasing application of ready-made mixtures. Their usage helps every household since it is not necessary to mix ingredients or to homogenize and store them separately. On the market, there are many ready-made mixtures for the preparation of various food products - pancakes, muffins, bread and bakery products, cereals, etc. [1-3].

\footnotetext{
* Corresponding author: aldurakova@abv.bg
} 
The ready-made mixture made of oatflakes, apples, and cinnamon is healthy food due to a number of properties of all three ingredients which are beneficial to human health. Oatflakes are ancient food which humanity has been consuming for more than 4000 years. They are rich in phosphorus, magnesium, potassium, copper, iron, and B5 vitamins and when consumed raw they contain great amounts of B1 and B9 vitamins. They have a low glycemic index, which means that they are slow to digest and do not affect considerably blood sugar or insulin. Oatflakes can be consumed by people suffering from Type 2 diabetes. What is more, oat-containing products contain beta-glucans, soluble fiber, which have been proven to decrease actively cholesterol levels, which may lower the risk of heart disease [4-7].

Apples are fruit which can be consumed throughout the year. They are tasty and high in nutrients which are beneficial in many respects to the human organism and human health. The main beneficial properties of apples are due to the great amounts of antioxidants and pectin. Apples protect against the harmful effects of free radicals and they simultaneously enhance the natural process of body detoxification. Owing to their high potassium amounts, apples constitute a natural diuretic. Their soluble fiber can lower the blood sugar levels of patients who are highly prone to acquire Type 2 diabetes [8-10].

The medicinal uses of cinnamon are due to the three active components in the essential oils in its bark: cinnamyl acetate, cinnamic aldehyde, and cinnamyl alcohol. Cinnamon is also an excellent source of manganese, fiber, iron, and calcium which are the most important nutrients in the human body [11-14]. A number of studies prove that cinnamon decreases the proliferation of leukemia and cancer cell lymphoma [15-18]. Other studies show that cinnamon contains some polyphenols which may help Type 2 diabetes patients to regulate their blood sugar levels [19]. A study published in the Diabetes Care journal in 2003 discovers that Type 2 diabetes patients, who have taken in on a daily basis between 3 and 6 grams of cinnamon for 40 days, lower their blood sugar levels by $18-29 \%$ [20].

The modelling of the sorption processes in organic food is very important with respect to choosing regimes of processing and storage. Major sorption characteristics of food products are equilibrium humidity and monomolecular moisture. The moisture of the products affects directly their texture, taste, flavor, quality, and safety during consumption. The excess or deficiency in water content may lead to earlier deterioration, worse quality parameters and effects. This is a basic parameter which is analyzed in different stages and with a greater or lesser intensity. Food samples are regularly tested in order to determine if water activity is maintained within the safety levels established by HACCP. The term "water activity - aw" was suggested for the first time by Scott in 1952 and is widely used in the monitoring of the Critical Control Points in Hazard Analysis Critical Control Point (HACCP) [21].

The in-depth literature review has not revealed data on any research concerning the sorption characteristics of ready-made mixtures containing oatflakes, apples, and cinnamon, which has encouraged us to carry out the present analysis.

\section{Materials and methods}

\subsection{Materials}

A ready-made mixture containing oatflakes, apples, and cinnamon purchased in Bulgaria from "Internet café-BG" Ltd, packed by "Zoya bg Organic Shop", certified by BG - BIO 18. 


\subsection{Sorption isotherms methods}

Moisture, $(\%)$ of the products studied - standard method via drying of $5 \mathrm{~g}$ of flour at $105^{\circ} \mathrm{C}$ to constant weight, according to AOAC, 1990 [22].

For the purposes of the present study, we used the static gravimetric method recommended by Project COST 90 and revised by Bell and Labuza, 2000 [23-24]. The analysis of sorption characteristics - adsorption and desorption - was conducted for temperatures of $10^{\circ} \mathrm{C}, 25^{\circ} \mathrm{C}$ and $40^{\circ} \mathrm{C}$ at eight different relative air humidities maintained via the saturated solutions of the following salts: $\mathrm{LiCl}, \mathrm{CH}_{3} \mathrm{COOK}, \mathrm{MgCl}_{2}, \mathrm{~K}_{2} \mathrm{CO}_{3}$, $\mathrm{Mg}\left(\mathrm{NO}_{3}\right)_{2}, \mathrm{NaBr}, \mathrm{NaCl}, \mathrm{KCl}$. The samples were dehydrated in advance in a desiccator above diphosphorus pentoxide $\left(\mathrm{P}_{2} \mathrm{O}_{5}\right)$ for 20 days, so that adsorption could be studied. For desorption, the samples were hydrated above distilled water $\left(\mathrm{H}_{2} \mathrm{O}\right)$. In order to conduct the analysis, we used aluminum weighing vessels in which we weighed samples being $1 \pm 0.01 \mathrm{~g}$ in mass. The vessels were placed in hygrostats in which we prepared in advance saturated solutions of salts maintaining above their surface specific constant water activities in the $0.11-0.85$ range. In the hygrostats, at water activity of $\mathrm{a}_{\mathrm{w}}>0.6$, we placed thymol crystals in order to prevent the microbiological deterioration of the product for the whole duration of the experiment. The hygrostats were placed in thermostats at the respective temperatures. Sample weighing was conducted every three days using an analytical balance with a precision of up to $0.0001 \mathrm{~g}$ until three equal values were reached (reaching the level of equilibrium moisture content).

The equilibrium moisture content $\mathrm{M}$ (\% dry mass) was determined via a dehydration method - for $24 \mathrm{~h}$ at $105^{\circ} \mathrm{C}$, the moisture content being calculated by the respective formula [22]. All tests were carried out in triplicate runs.

\subsection{Sorption characteristic modeling}

To describe sorption isotherms, we used the modified Oswin, Chung-Pfost, Halsey and Henderson three-parameter models. The mean relative error, the standard deviation, and the distribution of residuals were applied as criteria for the evaluation and comparison of the methods.

The Brunayer-Emmett-Teller (BET) model was transformed linearly in order to calculate the values of monolayer moisture content (MMC) [25]. Sorption characteristic modeling has been presented and described in detail by Durakova et al., 2020 [26].

\section{Results and discussion}

The ready-made mixture, purchased on the market, was characterized by the following percentages of the three components: wholegrain gluten-free oatflakes $-89.5 \%$; apples $10 \%$; cinnamon $-0.5 \%$ (bioingredients). The nutritive value of $100 \mathrm{~g}$ of product was: energy value $-1486 \mathrm{~kJ} / 352 \mathrm{kcal}$; protein $-11.6 \mathrm{~g}$; carbohydrate $-59.7 \mathrm{~g}$, of which sugars $6.7 \mathrm{~g}$; fat $-5.5 \mathrm{~g}$, of which saturated $-1.2 \mathrm{~g}$; fiber $-8.6 \mathrm{~g}$, and salt $<0.01 \mathrm{~g}$.

In order to analyze sorption characteristics, we dehydrated the ready-made mixture with an initial moisture content of $8.00 \%$ to $3.91 \%$ for adsorption and hydrated it to $17.60 \%$ for desorption. The equilibrium moisture content values for adsorption and desorption are shown in Tables 1 and 2. 
Table 1. Equilibrium moisture content $M, \%$ d.m. for adsorption at different temperatures $t\left({ }^{\circ} C\right)$ and water activities $a_{w}$

\begin{tabular}{lccccccccc}
\hline Sel & \multicolumn{3}{c}{$\mathbf{1 0}^{\circ} \mathbf{C}$} & & \multicolumn{2}{c}{$\mathbf{2 5}^{\circ} \mathbf{C}$} \\
$\mathbf{M}^{*}$ & $\mathbf{s d}^{* *}$ & $\mathbf{a}_{\mathbf{w}}$ & $\mathbf{M}^{*}$ & $\mathbf{s d}^{* *}$ & $\mathbf{a}_{\mathbf{w}}$ & $\begin{array}{c}\mathbf{4 0}^{\circ} \mathbf{C} \\
\mathbf{M}^{*}\end{array}$ & $\mathbf{s d}^{* *}$ \\
\hline $\mathbf{L i C l}$ & 0.113 & 3.66 & 0.17 & 0.113 & 2.55 & 0.05 & 0.112 & 1.92 & 0.04 \\
$\mathbf{C H 3 C O O K}$ & 0.234 & 4.39 & 0.40 & 0.225 & 3.55 & 0.17 & 0.201 & 2.50 & 0.14 \\
$\mathbf{M g C l}_{2}$ & 0.335 & 4.87 & 0.02 & 0.328 & 4.14 & 0.10 & 0.316 & 3.14 & 0.02 \\
$\mathbf{K}_{\mathbf{2}} \mathbf{C O}_{3}$ & 0.431 & 6.32 & 0.17 & 0.432 & 5.56 & 0.09 & 0.432 & 4.13 & 0.11 \\
$\mathbf{M g N O}_{3}$ & 0.574 & 8.35 & 0.48 & 0.529 & 7.36 & 0.02 & 0.484 & 5.43 & 0.36 \\
$\mathbf{N a B r}$ & 0.622 & 9.88 & 0.31 & 0.576 & 8.33 & 0.08 & 0.532 & 5.74 & 0.32 \\
$\mathbf{N a C l}$ & 0.757 & 9.97 & 0.27 & 0.753 & 8.39 & 0.39 & 0.747 & 7.87 & 0.65 \\
$\mathbf{K C l}$ & 0.868 & 14.22 & 0.46 & 0.843 & 14.09 & 0.28 & 0.823 & 9.34 & 0.48 \\
\hline
\end{tabular}

* Mean of three runs, ** Mean deviation of three runs

Table 2. Equilibrium moisture content $M, \% \mathrm{~d} . \mathrm{m}$. for desorption of different temperatures $t\left({ }^{\circ} \mathrm{C}\right)$ and water activities $a_{w}$

\begin{tabular}{|c|c|c|c|c|c|c|c|c|c|}
\hline \multirow[t]{2}{*}{ Sel } & \multicolumn{3}{|c|}{$10^{\circ} \mathrm{C}$} & \multicolumn{3}{|c|}{$2^{\circ} \mathrm{C}$} & \multicolumn{3}{|c|}{$40^{\circ} \mathrm{C}$} \\
\hline & $\mathbf{a}_{\mathbf{w}}$ & $\mathbf{M}^{*}$ & $\mathbf{s d}^{* * *}$ & $\mathbf{a}_{w}$ & $\mathbf{M}^{*}$ & $\mathbf{s d}^{* *}$ & $\mathbf{a}_{w}$ & M* & $\mathbf{s d}^{* *}$ \\
\hline LiCl & 0.113 & 2.59 & 0.28 & 0.113 & 2.32 & 0.11 & 0.112 & 1.89 & 0.07 \\
\hline СН3СОOК & 0.234 & 4.16 & 0.09 & 0.225 & 3.00 & 0.07 & 0.201 & 2.39 & 0.13 \\
\hline $\mathbf{M g C l}_{2}$ & 0.335 & 4.67 & 0.94 & 0.328 & 4.03 & 0.09 & 0.316 & 3.57 & 0.60 \\
\hline $\mathrm{K}_{2} \mathrm{CO}_{3}$ & 0.431 & 6.03 & 0.20 & 0.432 & 5.91 & 0.02 & 0.432 & 4.98 & 0.13 \\
\hline $\mathrm{MgNO}_{3}$ & 0.574 & 7.80 & 0.36 & 0.529 & 7.26 & 0.21 & 0.484 & 5.13 & 0.22 \\
\hline $\mathrm{NaBr}$ & 0.622 & 9.51 & 0.08 & 0.576 & 7.33 & 0.17 & 0.532 & 5.33 & 0.09 \\
\hline $\mathrm{NaCl}$ & 0.757 & 10.16 & 0.25 & 0.753 & 8.96 & 0.07 & 0.747 & 8.01 & 0.58 \\
\hline $\mathrm{KCl}$ & 0.868 & 13.77 & 0.50 & 0.843 & 13.45 & 0.53 & 0.823 & 9.14 & 0.42 \\
\hline
\end{tabular}

* Mean of three runs, ** Mean deviation of three runs

For both processes, we observed a behavior typical of many food products under study, namely that the increase in temperature at constant water activity is coupled by a decrease in equilibrium moisture content [27-31].

Figure 1 shows the comparison of isotherms at a temperature of $10^{\circ} \mathrm{C}$. It is evident that the isotherms belong to Type III according to the classification of Brunauer et al., 1940 [32].

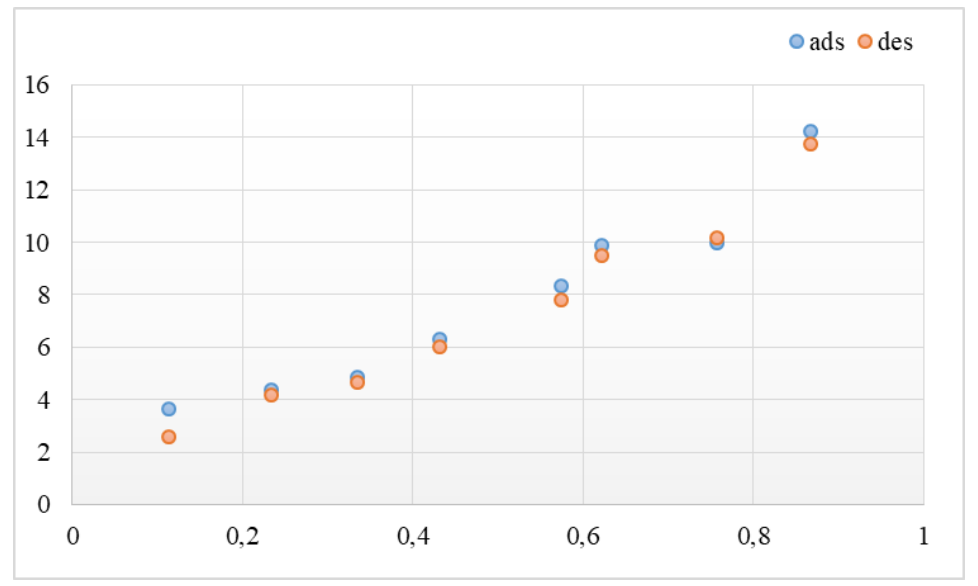

Figure 1. Comparisons of isotherms at $10^{\circ} \mathrm{C}$ 
In the present study, the obtained coefficients of the three-parameter models $(A, B, C)$ and the corresponding values of mean relative error P,\%, standard deviation SEM and distribution of residuals are shown in Table 3 for adsorption and in Table 4 for desorption.

Table 3. Coefficients of the models (A, B, C), average relative error P, $\%$ and standard deviation SEM for adsorption

\begin{tabular}{lcccccc}
\hline Model & $\boldsymbol{A}$ & $\boldsymbol{B}$ & $\boldsymbol{C}$ & $\boldsymbol{P}$ & $\boldsymbol{S E M}$ & Residuals \\
\hline Oswin & $\mathbf{7 . 7 0 8 4}$ & $\mathbf{- 0 . 0 6 1 5}$ & $\mathbf{0 . 3 9 9 6}$ & $\mathbf{9 . 8 7}$ & $\mathbf{0 . 8 9}$ & arbitrary \\
Halsey & 2.7094 & -0.0186 & 1.4806 & 13.61 & 1.92 & non-arbitrary \\
Henderson & 0.0007 & 31.865 & 1.5606 & 11.38 & 0.99 & non-arbitrary \\
Chung-Pfost & 217.48 & 0.2621 & 35.536 & 12.94 & 0.97 & non-arbitrary \\
\hline
\end{tabular}

Table 4. Coefficients of the models (A, B, C), average relative error P, $\%$ and standard deviation SEM for desorption

\begin{tabular}{lcccccc}
\hline Model & $\boldsymbol{A}$ & $\boldsymbol{B}$ & $\boldsymbol{C}$ & $\boldsymbol{P}$ & $\boldsymbol{S E M}$ & Residuals \\
\hline Oswin & 7.2853 & -0.0521 & 0.4115 & 9.66 & 0.70 & non-arbitrary \\
Halsey & 2.4055 & -0.0131 & 1.4024 & 14.62 & 2.02 & non-arbitrary \\
Henderson & $\mathbf{0 . 0 0 0 6}$ & $\mathbf{4 4 . 6 7 2}$ & $\mathbf{1 . 5 3 9 9}$ & $\mathbf{8 . 3 5}$ & $\mathbf{0 . 6 9}$ & arbitrary \\
Chung-Pfost & 268.60 & 0.2606 & 52.471 & 9.96 & 0.77 & non-arbitrary \\
\hline
\end{tabular}

The data show that the lowest values of P and SEM and arbitrary distributions of residuals for adsorption were obtained by the modified Oswin, whereas for desorption - by the modified Henderson. As a result, we can recommend both models. For the description of the adsorption isotherms of the ready-made mixture containing oatflakes, apples, and cinnamon, we recommend the modified Oswin, whereas for the description of the desorption isotherms of the mixture we recommend the modified Henderson.

In order to calculate MMC, we had to linearize the Brunauer-Emmett-Teller equation. The linearization using test data for $\mathrm{a}_{\mathrm{w}}<0.5$ in the case of adsorption and desorption is shown in Fig. 2 and 3 [25].

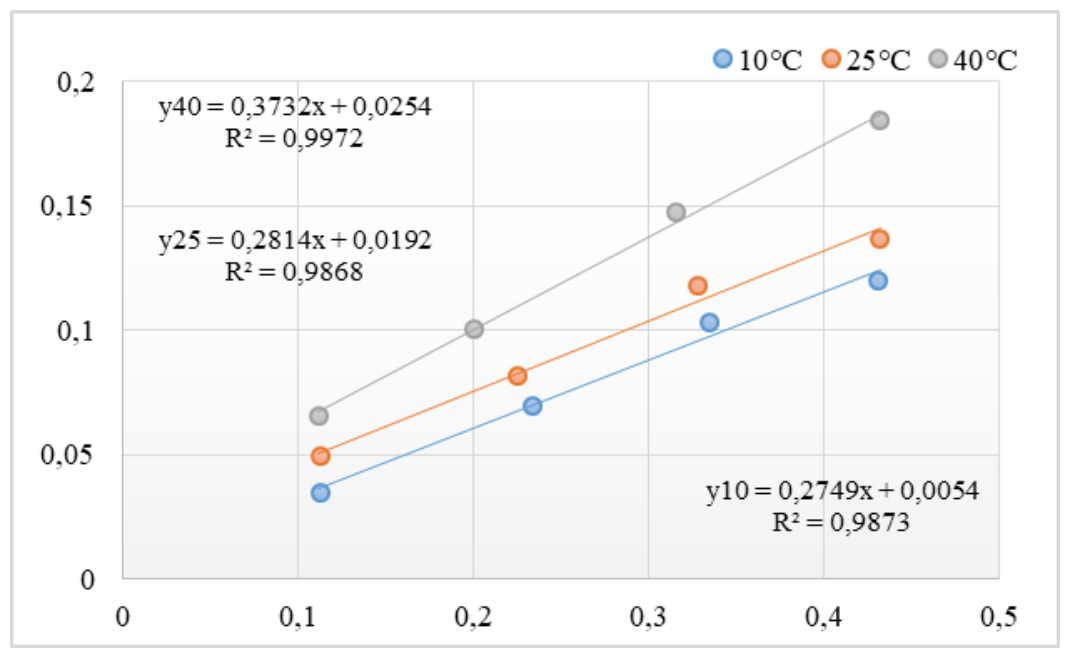

Figure 2. Linearization of the BET model at different temperatures for adsorption 


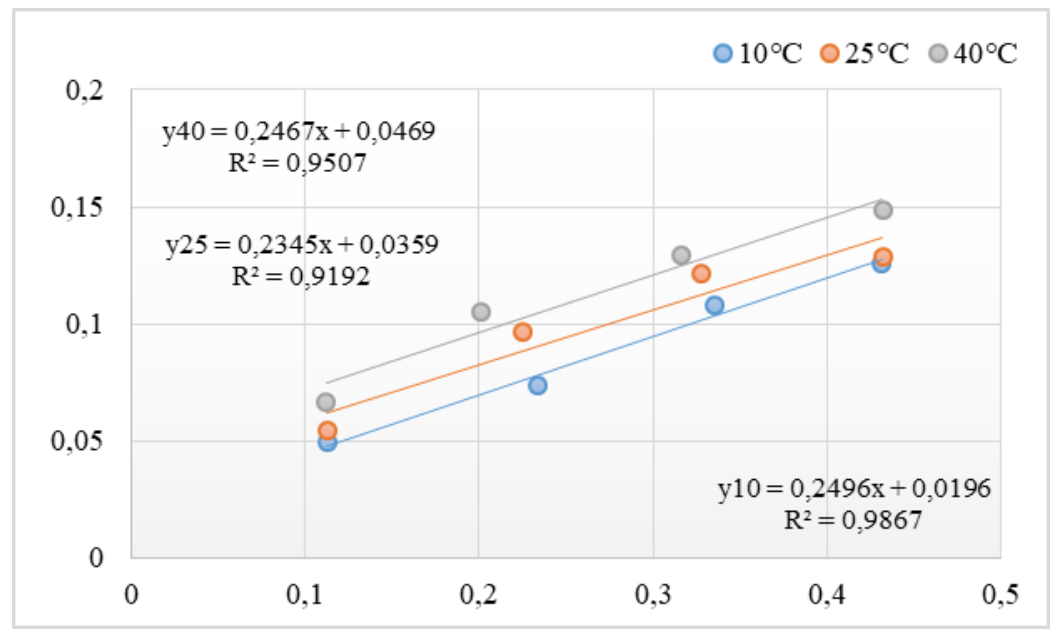

Figure 3. Linearization of the BET model at different temperatures for desorption

On the basis of the coefficients obtained from the linear equations, we calculated the MMC values for both processes and the three temperatures, as shown in Table 5. The value of monomolecular moisture (MMC) is a sorption characteristic which affects the stability of the food product. A number of studies prove that when the product under storage reaches a value corresponding to $\mathrm{MMC}$, it preserves its qualitative parameters [33].

Table 5. BET monolayer moisture content, $\%$ d.m. at different temperatures $\left(t,{ }^{\circ} \mathrm{C}\right)$ for adsorption and desorption

\begin{tabular}{ccc}
\hline $\boldsymbol{t} \boldsymbol{(} \boldsymbol{C})$ & Adsorption & Desorption \\
\hline $\mathbf{1 0}$ & 3.57 & 3.71 \\
$\mathbf{2 5}$ & 3.33 & 3.70 \\
$\mathbf{4 0}$ & 2.51 & 3.41 \\
\hline
\end{tabular}

The data show that temperature affects MMC. The increase in temperature is coupled by a decrease in MMC values for both processes. In the case of adsorption, MMC diminishes by $1.06 \%$ from $10^{\circ} \mathrm{C}$ to $40^{\circ} \mathrm{C}$, while with desorption it is lowered by $0.3 \%$. On the basis of the obtained results, we can predict that in the case of mixture moisture content in the $2.51 \%$ d.m. $-3.71 \%$ d.m. range there will be microbial load for a greater period of time [24].

\section{Conclusions}

1. We obtained the equilibrium moisture content data for adsorption and desorption of a ready-made mixture containing oatflakes, apples, and cinnamon at temperatures of $10^{\circ} \mathrm{C}$, $25^{\circ} \mathrm{C}$ and $40^{\circ} \mathrm{C}$ and relative air humidities in the $0.11-0.85$ range.

2. We established that the increase in temperature leads to a decrease in equilibrium moisture content at constant water activity.

3. We discovered that the isotherms of the product under study belong to Type III according to the classification of Brunauer et al. 
4. For the description of the adsorption isotherms of the ready-made mixture containing oatflakes, apples and cinnamon, we recommended the modified Oswin, while for the description of desorption isotherms we suggested the modified Henderson.

5. The modified models of Oswin and Henderson, suggested for the description of the sorption characteristics of the ready-made mixture of oat flakes, apple, and cinnamon can be used to make predictions concerning the equilibrium humidity relative to the experimental conditions.

6. On the basis of the linearization of the Brunauer-Emmett-Teller model, we calculated the MMC values for adsorption and desorption using test data for $\mathrm{a}_{\mathrm{w}}<0.5$ in the case of adsorption within the $2.51 \% \mathrm{~d} . \mathrm{m} .-3.57 \% \mathrm{~d} . \mathrm{m}$. range and in the case of desorption - in the $3.41 \%$ d.m. $-3.71 \%$ d.m. range.

7. We established that, as regards the ready-made mixture containing oatflakes, apples, and cinnamon, temperature affects $\mathrm{MMC}$ values. With the increase in temperature, the values are decreased from $10^{\circ} \mathrm{C}$ to $40^{\circ} \mathrm{C}$ by $1.06 \%$ for adsorption and by $0.3 \%$ for desorption.

\section{Acknowledgements}

This study was part of the "FS N11/20-H" Scientific Research Fund, project director: Assoc. Prof. PhD Albena Georgieva Durakova, University of Food Technologies - Plovdiv, Bulgaria.

\section{References}

1. I. Y. Reznichenko, D. M. Borodulin, A. M. Chistyakov, N.Y. Ruban, S. S. Komarov, IOP Conf Ser Earth Environ Sci, 613 (1), 012124, IOP Publishing. (2020).

2. M. H. Mughal, BJSTR, 18 (4), 13804-13811, (2019).

3. A. Bogoeva, A. Durakova, R. Vrancheva, A. Slavov, BJAS, 26 (4), 906-912 (2020).

4. S. Al-Hooti, J. S. Sidhu, J. Al-Otaibi, H. Al-Ameeri, H. Al-Qabazard, Plant Foods Hum Nutr., 51 (2), 125-135, (1997).

5. X. - Z. Hu, J. - M. Zheng, X. - P. Li, C. Xu, Q. Zhao, J. Cereal Sci., 60 (2), 297-301, (2014).

6. H. G. Liljeberg, Y.E. Granfeldt, I. M. Björck, J Nutr, 126 (2), 458-466, (1996).

7. B. D. Singu, P. R. Bhushette, U.S. Annapure, Food Bioproc Tech., 1-12, (2020).

8. M. Lauková, Z. Kohajdová, J. Karovičová, Potr. S. J. F. Sci., 10 (1), 506-511, (2016).

9. R. C. Skinner, J. C. Gigliotti, K. M. Ku, J. C. Tou, Nutr. Rev., 76 (12), 893-909, (2018).

10. M. O. Al-Shawwa, Classification of Apple Fruits by Deep Learning, (2020).

11. K. Singletary, Nutr. Today, 54 (1), 42-52, (2019).

12. F. Askari, B. Rashidkhani, A. Hekmatdoost, Nutr Res, 34 (2), 143-148, (2014).

13. T. Bandara, I. Uluwaduge, E. R. Jansz, Int. J. Food Sci. Nutr, 63 (3), 380-386, (2012).

14. P. Ranasinghe, S. Pigera, G. S. Premakumara, P. Galappaththy, G. R. Constantine, P. Katulanda, BMC Complement Altern. Med., 13 (1), 275, (2013).

15. J.-E. Kim, J. E. Son, H. Jeong, D. J. Kim, S. G. Seo, E. Lee, T. G. Lim, J. R. Kim, Y. R. Kimbung, H. Chen, A. M. Bode, K. W. Lee, Z. Dong, Cancer Res., 75 (13), 27162728, (2015). 
16. J. Gruenwald, J. Freder, N., Armbruester, Crit Rev Food Sci Nutr, 50 (9), 822-834, (2010).

17. S. A. Almatroodi, M. A. Alsahli, A. Almatroudi, S. Anwar, A. K. Verma, K. Dev, A. H. Rahmani, Gene Rep., 100966, (2020).

18. B. Goel, S. Mishra, Eur J Med plants, 10-16, (2020).

19. V. Assadollahi, K. Parivar, N. H. Roudbari, A. R. Khalatbary, M. Motamedi, B. Ezatpour, G. R. Dashti, (2013). Adv. Biomed. Res., 2, (2013).

20. A. Khan, M. Safdar, M. M. A. Khan, K. N. Khattak, R. A. Anderson, Diabetes care, 26 (12), 3215-3218, (2003).

21. E. Sandulachi, Technical University of Moldova, 42-43, (2012).

22. AOAC, 960.39 (Washington, DC), 15 ed. AOAC, (1990).

23. W. Wolf, W. Spiess, G. Jung, G. In Properties of water in foods, 661-679, Springer, Dordrecht, (1985).

24. L. Bell, T. Labuza, AACC, 33-36, (2000).

25. S. Brunauer, P.H. Emmett, E. Teller, JACS, 60 (2), 309-319, (1938).

26. A. Durakova, A. Bogoeva, V. Yanakieva, T. Gogova, K. Choroleeva, E3S Web of Conferences, 180, 03007, EDP Sciences, (2020).

27. A. Durakova, A. E3S Web of Conferences, 180, 03008. EDP Sciences, (2020).

28. A. Bogoeva, JCEA, 21 (3), 609-617, (2020).

29. T. P. Labuza, B. Altunakar, Water activity in foods: fundamentals and applications, Chapter 7, 161-205, John Wiley \& Sons, Inc, (2020).

30. A. W. Gichau, J. K. Okoth, A. Makokha, JFST, 57 (3), 962-970, (2020).

31. S. Al-Ghamdi, Y. K. Hong, Z. Qu, S. S. Sablani, J. Food Eng., 273, 109820, (2020).

32. S. Brunauer, L. S. Deming, W. E. Diming, E. Troller, JACS, 62, 1723-1732, (1940).

33. S. Kaya, \& T. Kahyaoglu, J. Food Eng., 71 (2), 200-207, (2005). 